\title{
The privacy problem for internalizing behavioral externalities
}

\author{
MATTHEW JEFFERS*
}

Hartford, CT, USA

Received: February 22, 2020 • Revised manuscript received: October 1, 2020 • Accepted: November 3, 2020

Published online: December 4, 2020

(C) 2020 The Author(s)

\section{ABSTRACT}

Providers of insurance used to have no other choice than to absorb the behavioral externalities of their policy-holders. New technology coupled with the incentives of low-risk consumers has made it possible for firms to price-discriminate on the basis of behavioral risk and thus internalize behavioral externalities. While cost-internalization is generally a positive development, the introduction of behavioral tracking technologies also introduces new economic and social costs. This paper explores the economic and moral trade-offs of adopting behavioral tracking technologies in various insurance settings.

\section{KEYWORDS}

privacy, behavioral externalities, pooling equilibria, separating equilibria, asymmetric information, price discrimination

JEL CLASSIFICATION INDICES

D62, D82

\section{INTRODUCTION: TWO TYPES OF EXTERNALITIES}

Internalizing some cost $\mathrm{X}$ that is externalized by party $\mathrm{A}$ onto party $\mathrm{B}$ is a natural economic and moral aim. From an economic standpoint, a negative externality is inefficiency because party A is not bearing the costs of their activities and thus overproduces some activity (Pigou 2013). From a moral standpoint, most externalities involve a harm or damage that is inflicted on some

\footnotetext{
*Corresponding author. E-mail: jeffers.matt7@gmail.com
} 
innocent party B that takes no part in the activity caused by party A. ${ }^{1}$ Therefore, it would be more efficient and more conducive to justice if party A was made to bear the full costs of their activities as doing so would properly incentivize party A to produce the optimal amount of some activity and would eliminate or reduce the harm that party B suffers.

Overuse of particular commodities is commonly listed as the type of activity where costinternalization could help such as taxing $\mathrm{CO}_{2}$ emissions to reduce the carbon footprint or taxing plastics to reduce microplastic prevalence in aquatic resources. What is notable about these examples is that the resource being overproduced is either a commodity or the byproduct of a commodity. But many other types of externalities do not involve commodities but behaviors. Reckless driving, loud music, second hand smoke, public intoxication all constitute behaviors that generally create negative externalities for others. As global population grows and cities become denser, the effect of behavioral externalities increases in magnitude.

Traditionally, behavioral externalities deviate from resource externalities in that they cannot be easily taxed or fined. It is straightforward to tax products or their production but it is not so easy to tax risky social behavior such as reckless driving, public nuisances, or unsafe firearm storage. Personal behavior can often be ephemeral, its risk or harm diffusely spread, and its origin sometimes known only to the behavioral perpetrator. However, with the increasing digitization of personal information, the advent of big data and artificial intelligence (AI), the monitoring of personal and behavioral information is increasingly feasible.

Providers of many types of services, typically insurance services, used to have no other choice than to absorb the behavioral externalities of their constituents or policy-holders. New technology coupled with the incentives of low-risk consumers has made it possible for both firms and governments to price-discriminate on the basis of behavioral risk and thus internalize behavioral externalities. The mechanism for this is as follows: providers of insurance responsible for paying for the costs of externalized behavior will want to lower these costs by internalizing them to individuals responsible for this behavior. To do so, they will need to distinguish between those individuals bearing low-risk from those individuals bearing high-risk and price-discriminate between them. To properly price-discriminate, they will need to gather personal and behavioral information on everyone they are insuring. To gather this information, firms have begun implementing behavioral tracking technologies, henceforth referred to as BTTs. Gathering behavioral information can allow firms to properly price-discriminate and hence better internalize costs between low and high risk individuals. While cost-internalization is generally a positive development, the introduction of BTTs also introduces new economic and social costs. This paper explores the trade-offs of adopting BTTs in various socio-economic settings.

I begin by briefly reviewing the relevant economic literature on insurance markets and the relevant social theory literature on privacy. Then, I define the methodology in which I analyze the effectiveness of insurance schemes using four normative criteria. I then lay out the general model of why organizations have an incentive to cost-internalize behavioral externalities using BTTs and why prima facie this is a social and economic improvement. I then introduce the distinction between insurance consumers that are privacy-lovers from those who are privacyindifferent. This new distinction complicates the initial economic analysis and makes it much more ambiguous whether BTTs improve the insurance market according to our four normative

\footnotetext{
${ }^{1}$ Most, but not all. Some externalities are co-committed, e.g., traffic congestion.
} 
criteria. The remainder of the paper analyses the trade-offs of adopting BTTs in two different insurance contexts using our normative criteria. The paper concludes with a summary of the social and economic implications of adopting BTTs.

\section{LITERATURE REVIEW}

People purchase insurance to trade a known quantity of small loses to safeguard a future state from much larger losses. Ideally, insurance is intended to only protect against external risks that the agent faces, since the agent cannot control those kinds of risks. In reality, the insurable individuals themselves often play a significant role in determining their overall risk level. For example, people can drive cautiously or recklessly, they can eat healthily or poorly, they can exercise, or be lethargic, etc. These choices have significant implications for a person's overall risk-level and increase their probability for trigging an insurable event for automobile, medical, and life insurance. An individual's risk-level across these parameters has traditionally been unknown to insurance firms (Rothschild - Stiglitz 1978). Accordingly, the literature on insurance has typically divided insured populations into two groups: low-risk and high-risk. A dilemma that insurance companies face is how to price insurance policies knowing that individuals possess diverse risk profiles. Given the uncertainties that insurance firms face when selling policies to individuals of different risk-profiles, economists have offered competing accounts on whether the insurance market finds equilibrium and the properties that such an equilibrium would possess.

In the past several decades two competing views on insurance markets have emerged. The first view, originally articulated by Rothschild and Stiglitz (1978), held that competitive insurance markets were susceptible to either (a) having no market equilibrium or (b) having a separating equilibrium in which members of both groups (low-risk individuals and high-risk individuals) are only partially insured. The problem according to this group of theorists is that "the presence of the high-risk individuals exerts a negative externality on the low-risk individuals", making the market less efficient than it otherwise would be (Rothschild and Stiglitz 1978: 638). Under this account, the problem is one of asymmetric information, where individuals have relatively more information about their own risk-profiles then insurance companies do. One assumption of the Rothschild and Stiglitz model is that high-risk individuals are more likely to purchase insurance in the first place because they are more likely to benefit from coverage, while low-risk individuals are less likely to purchase insurance as they are less likely to benefit from coverage. Knowing this, insurance companies are inclined to offer a menu of policies that charge prices at higher rates for individuals seeking more coverage and lower prices to individuals seeking less overall coverage (Rothschild - Stiglitz 1978; Spence 1978; Wilson 1976). The relative size of low risk to high risk individuals determines the extent to which no equilibrium is obtained or a separating equilibrium is obtained (Rothschild - Stiglitz 1978).

In opposition to the Rothschild-Stiglitz view, another conception has emerged that challenges the underlying assumptions of the original model. De Meza and Webb (2001) contend that individuals do not generally have identical risk preferences but instead argue that "cautious people are not only more inclined to buy insurance but also put more effort into limiting risk exposure, compared to individuals of a more reckless disposition" (De Meza - Webb 2001: 250). According to this view, as low risk-individuals enter the insurance market, the cost of insurance 
is driven down overtime due to market competition. As the price of insurance falls, high-risk individuals are now induced to enter the insurance market. The result is that low-risk individuals subsidize high risk individuals in pooling equilibria. Ultimately, "risk-tolerant individuals take few precautions and are disinclined to insure, but they are drawn into a pooling equilibrium by the low premiums created by the presence of safer, more risk-averse types" (De Meza - Webb 2001: 249).

While the Rothschild-Stiglitz and Meza-Webb conceptions of the insurance market are strikingly different, they both hold that uncertainties in distinguishing between high and low risk individuals culminate in sub-optimal distribution of insurance holdings. Under the RothschildStiglitz Model, equilibrium is either impossible or a separating equilibrium results in only partial coverages where low-risk individuals subsidize high-risk individuals. In the Meza and Webb Model, the presence of lower premiums due to low-risk types draws in high-risk individuals to become insured, which results in a partial-pooling equilibrium where again low-risk individuals subsidize high risk individuals. The models disagree about the level of coverage obtained by the two groups, but they both agree that informational uncertainties generate a subsidy from lowrisk to high-risk individuals.

The emergence of behavioral tracking technologies (BTTs) can considerably diminish the informational asymmetries that cause these sub-optimal economic consequences. BTTs can be used by insurers to paint a comprehensive portrait of each insured individual's risk level. Our medical records are in possession by clinics and hospitals, our grocery purchases are known by credit card companies, and our lifestyle habits are knowable by online search firms, e-commerce organizations, and cell-phone companies. This information could reveal whether our dietary habits are healthy, how much alcohol we consume, whether we get enough exercise and ultimately how long we are expected to live. Were this information made available to insurance companies it could provide a very accurate and personalized assessment of an individual's level of behavioral risk.

While economists would likely see BTTs as offering considerable economic improvements in the insurance market, some social theorists are increasingly wary of the cultural risk that big data and artificial intelligence pose to society at large. The concerns that these social theorists raise are also applicable to BTTs. A relatively straightforward concern is that the presence of behavioral tracking technology means that it becomes possible for private firms to continuously monitor and surveil their customers. In particular, Zuboff identifies the emergence of a "new universal architecture. . . a ubiquitous networked institutional regime that records, modifies, and commodifies everyday experience from toasters to bodies, communication to thought, all with a view to establishing new pathways to monetization and profit" (Zuboff 2015: 81). This network of behavioral tracking technology coupled with the power of artificial intelligence could generate the perverse consequence that firms will know "far more about its populations [of customers] than they know about themselves" (Zuboff 2015: 83). The upshot for consumers is that companies are now better situated to price discriminate against them by using the very information that consumers voluntarily surrender. Newman argues that tracking technologies in online marketing enables the firm to identify each customer's unique pain point and create a custom price for each individual (Newman 2014). Such a setup allows firms to extract virtually all of the gains from trade thereby minimizing consumer surplus. In section six I discuss how a similar argument may be levied at BTTs which reduces the social subsidy function of insurance and potentially price individuals out of the insurance market. 
A third major concern for social theorists is the dissolution of both privacy norms and privacy rights. Historically, threats to privacy were a byproduct of government overreach. The introduction of tracking technologies has created a new paradigm in which "public and private surveillance are simply related parts of the same problem, rather than wholly discrete" (Richards 2013: 1935). The mere existence of new information generated by tracking technology creates an increased privacy risk as the new data could be stolen, compromised, or disclosed to other parties for purposes beyond its original use. This information would be highly prized by marketers, transportation agencies, ride-sharing firms, law enforcement, and criminals. Law enforcement are already taking advantage of similar private databases for investigative purposes, most notably in the case where genetic data from the company GEDmatch was used to catch the Golden State Killer (Guerrini et al. 2018). Using the powers of legislation, regulation, or through juridical means, government entities have the tools necessary to co-opt and use this data for their own purposes. The social consequence is that "individuals are increasingly monitored by an overlapping and entangled assemblage of government and corporate watchers" (Richards 2013: 1935).

\section{METHODOLOGY}

From the standpoint of traditional economic analysis, the introduction of BTTs to the insurance market would be a welcome innovation as it would allow insurers to properly distinguish between low and high-risk individuals who will have marked efficiency improvements as I will discuss in section four and five. However, social theorists such as Richards (2013), Newman (2014), and Zuboff (2015) have identified certain disconcerting features of an increasingly networked world. In particular, they point out how BTTs and other similar "innovations" will result in a markedly less private world and one saturated by intrusive artificial intelligence. Economists and social theorists have noticeably different visions of a future of behavioral tracking technologies. In what follows I hope to reconcile these two differing visions by exploring the trade-offs that adoption of BTTs in the broader insurance market would bring about. The aim is to obtain a more balanced sense of the social and economic advantages and disadvantages of BTTs.

To determine the various trade-offs of BTTs in the insurance domain I use four traditional normative criteria: economic efficiency, incentives, rewards, and social risk. I give a brief account of each of the criteria in turn.

1. Economic efficiency is measured by the size of the social surplus. Efficiency is improved if the total surplus is increased and is reduced if the total surplus decreases. The primary mechanism through which BTTs improve efficiency is by better internalizing costs which in turn results in a separating equilibrium and thus causes improved purchasing efficiency by both high and low risk individuals. However, as we will see this will be complicated by the privacy preferences of consumers.

2. Incentives are improved if individuals are better incentivized to decrease socially risky or harmful behavior. BTTs purportedly improve incentives by better internalizing insurance costs based on an individual's behavior.

3. Rewards/punishments are improved if individuals are rewarded for socially beneficial behavior and punished for socially costly behavior. However, individuals could also be 
rewarded or punished for having particular preferences, which is a detriment to both efficiency and individual liberty. Thus, we will also be analyzing whether rewards and punishments using BTTs go beyond their intended purview.

4. The social risk category is a catch-all for concerns that are larger than the welfare of the individuals in the identified groups. That is, risks that cannot be situated within an individual's utility function. Notable examples include fundamental rights, such as the right to privacy, or the right to health insurance, or even issues of social stability, and harmony.

Next, I lay out the general model of cost-internalizing behavioral externalities.

\section{THE GENERAL MODEL OF COST-INTERNALIZING BEHAVIORAL EXTERNALITIES}

Every insurer knows that the policy-holders covered under their plans pose varying degrees of behavioral risk. ${ }^{2}$ Assume that everyone an insurer covers could either be categorized in a lowrisk or a high-risk group. If insurers do not distinguish between people based on risk levels, it means that they have to aggregate rates across risk groups, meaning that everyone gets the same price for the same policy regardless of their risk level. This results in a situation where the lowrisk customers are essentially subsidizing the policies of the high-risk customers. There are four problems with this, two economic and two moral.

The economic problems include deadweight loss and adverse selection. For a low-risk customer, the price of the policies might be so high that they are discouraged from purchasing a policy. This means a transaction that would have been beneficial to both parties is foregone, i.e., there is deadweight loss. There is not only too little of the "right" kind of demand, but also too much of the "wrong" kind of demand, namely too many high-risk individuals will purchase this policy and thus the balance of insurance payouts to these individuals will exceed the costs that these individuals are paying in to the system. For the insurer, having to aggregate across risk groups would mean a higher chance of losing the business of low-risk customers and a higher chance of losing money on providing disproportionately cheap insurance policies to high-risk customers. These effects decrease the stability of the insurance market in the long run (Rothschild - Stiglitz 1978).

The moral issues are two-fold: low behavioral risk consumers are priced out of the market and high behavioral risk customer's free-ride on low behavioral risk customers. First, suppose a person decides to become uninsured because the market price has become too high. If bad luck strikes, this uninsured individual is now wholly responsible for footing the bill, and it is because they were priced out of the market by people taking on higher risks, a rather perverse result. Second, if a person in the low-risk category decides to purchase a policy, it means that they are paying more so that people who have riskier behaviors pay less, which unfairly punishes low-risk individuals. $^{3}$

\footnotetext{
${ }^{2}$ I am only concerned about risk that is attributable to the behavior of the agents being insured. In saying this, I am not precluding these risk considerations from an insurer's calculus. The model described here does not depend on ignoring these features; it just says nothing about them at all.
}

${ }^{3}$ This means that high-risk customers are free-riding on low-risk customers. 
So, it would be preferable if we could distinguish between low-risk and high-risk customers so that insurers can charge rates on the basis of relative behavioral risk. The adoption of BTTs enables insurers to accurately distinguish between the two groups. BTTs allow the insurance company to charge lower prices to lower risk customers and higher prices to higher risk customers, which better internalizes costs. Economically, this gets us closer to the Pareto frontier, though interestingly it is not a Pareto improvement from the original circumstance. ${ }^{4}$ This is simply because one party, the high-risk group, is now having to pay more to cover the insurance for that risk. From the perspective of consumer advocates, it would generally count against a practice if it moved from charging a given individual a lesser price to a higher price for the same service, but in this case, it counts in its favor. Under a system where an individual's payment is based on the aggregate risk profile of a group, that individual has little incentive to reduce their own level of risk, and in fact they might have an incentive to increase their level of risk, especially if it comes with a private reward that exceeds the expected private cost. By contrast, if the price of insurance goes down with low-risk behavior and goes up with high-risk behavior, then it creates an incentive for the insured to partake in less risky behaviors. One of the economic advantages of behavioral price-discrimination is that it creates an incentive to reduce social risk. One of the moral advantages of behavioral price discrimination is that it means individuals causing more social risk pay a higher cost for doing so, while individuals causing less social risk pay a lower cost (Dworkin 1981). From the standpoint of making individuals accountable for their own risks and reducing the costs of those risks to others, this is a moral improvement as it rewards those who decrease social risk and punishes those who increase it.

All considered then, internalizing behavioral externalities reduces social costs, decreases the possibility that adverse selection bankrupts insurance companies, optimizes rewards by making people pay in proportion to the level of behavioral risk they pose to society, and encourages personal responsibility. These are all positive developments. From the preliminary analysis, this looks like a win-win-win. We now turn to take a look at how this is playing out in the car insurance market.

\section{COST-INTERNALIZATION OF RISKY DRIVING IN CAR INSURANCE}

Traditionally, car insurers had limited means to price-discriminate between safe and risky drivers, they typically had to rely on using historical data or statistical demographic commonalities. The introduction of BTTs, specifically "telematic devices," have enabled car insurers to collect real-time data on the driving patterns of their policyholders (Guillen 2018). These devices are designed to track a number of driving behaviors, including but not limited to: how often a person drives, how "hard" a person breaks, how fast a person drives, seat belt usage, lane changes, and vehicle location (Husnjak et al. 2015). The use of this data allows car insurance companies to determine the level of risky behavior that a driver is engaged in and then adjust insurance rates accordingly.

Drivers agree to this under the promise of lower car insurance rates for demonstrating safe driving behavior. Interestingly, this works as a price-discrimination method even if risky drivers

${ }^{4}$ One can move toward the Pareto frontier, without that movement being a Pareto improvement (Buchanan and Tullock 1965). 
choose not to participate in the program. If driver's self-select participation based on their own assessment of how well they drive, then safe drivers are more likely to opt into the program and risky drivers are more likely to opt out. Insurance companies are aware that this self-selection may occur and then need only monitor and adjust their default car insurance rates at levels for insuring riskier drivers and then can incentivize participation in the program for the prospect of either temporary or permanent rate reductions. As knowledge of these programs become more widespread, it becomes more likely that drivers who opt out of the telematic device program are risky drivers, while those who opt-in are revealed to be either risky or safe-drivers based on the data obtained from the device. This gives the insurer the information they need to accurately price customers. Over the long run, as adoption of these telematic devices becomes the norm, insurers will be able to provide personal rates corresponding to the precise level of behavioral risk that the customer poses.

If the general model is accurate, then using our established normative criteria we should expect the following implications: (1) a separating equilibrium that efficiently internalizes costs, (2) low-risk individuals are rewarded with lower insurance premiums, (3) high-risk drivers are punished with higher insurance premiums, (4) an incentive for high-risk individuals to adopt low-risk behavior, and (5) fewer car accidents in the long run. If the model is an accurate representation of what will happen in the car insurance marketplace, the result is overwhelmingly positive. Yet, this analysis may fail to capture the long-term costs. We have thus far assumed that consumers are completely indifferent to the privacy concerns that BTTs pose. In the next section, we show how the introduction of differential privacy preferences complicates this analysis.

\section{RISKS FROM COST-INTERNALIZATION OF BEHAVIORAL EXTERNALITIES IN A COMPETITIVE MARKET}

Historically, consumers used to only have two options when it came to insuring themselves against some risk, either buy insurance (at some level) or don't buy insurance. In the previous two sections we assumed that consumers would generally stay with their insurance plan and that the only difference would be whether they opt-in or opt-out of the behavioral tracking program. Of course people sometimes do choose to be uninsured when they perceive that the cost of the program exceeds the expected value of the risk. With the advent of BTTs, such as the previously mentioned telematic devices, consumers now have three options: (1) opt-in to the insurer's behavioral tracking program to obtain a lower insurance rate, (2) purchase insurance but optout of the insurer's behavioral tracking program to preserve privacy and pay a higher insurance rate, or (3) decline insurance altogether. I use the following designations to refer to the respective options: "Insured + Opt-In", "Insured + Opt-Out", "Uninsured". So, given these three options how will consumers choose?

Our prior model assumed that there were only two relevant groups, people who posed low risks and those who posed high risks. However, we can plausibly assume another relevant dimension of consumer preference; those who are indifferent to privacy loss and those who bear a utility loss when they lose privacy in some domain. The former group we can call privacy indifferent, while the latter are privacy lovers. Thus, for any particular cost-internalizing 
Table 1. Types of insurance consumers

\begin{tabular}{|l|c|c|}
\hline & Low risk & High risk \\
\hline Privacy indifferent & Group A: (Low risk, Privacy Indifferent) & Group B: (High Risk, Privacy Indifferent) \\
\hline Privacy lovers & Group C: (Low Risk, Privacy Lovers) & Group D: (High Risk Privacy Lovers) \\
\hline
\end{tabular}

Source: Author.

technology or method that creates a privacy risk, there are actually four relevant consumer groups. See Table 1.

The level of risk and the preferences of the participants will determine their behavior. As we know from our discussion in sections four and five, Group A will adopt the behavioral tracking technology because they will receive a lower insurance premium than if they were pooled with the high risk group. However, this is the only group of consumers where we can be confident what all of its members will do. For the members in each of the other groups, their behavior does not clearly cleave in a single direction, but will depend on the specific details of each individual's utility function. However, we can provide the general behavioral contours for the consumers in each group. Participants of Group B would have insurance absent the existence of the behavioral tracking technology. However, the introduction of this technology means that the increased risk that this group poses makes their premiums much higher than they were previously. The consequence is that some consumers in Group B will likely leave the insurance market altogether. The remaining members of Group B value having insurance even given the higher premiums. Thus the remaining members of Group B will remain insured but will initially optout of the BTT program. In the long run, members of this sub-group will have an incentive to make behavioral changes to decrease their level of risk.

Members of Group C are low-risk privacy lovers which puts them in the unfortunate position of having to sacrifice either privacy, cost, or insurance. They can only opt-in to the behavioral tracking program at the expense of their preference for privacy. Some members will take this route, meaning that they receive a premium discount but also suffer a utility loss from decreased privacy. For the other members of Group C, those who value a high degree of privacy, they have a difficult choice. If they choose "Insured + Opt-Out", they will be pooled with highrisk individuals and have to pay significantly higher premiums than they currently pay. If they choose "Uninsured" then in the unlikely event that they have an accident, they will be unprotected. None of these options looks particularly attractive from the standpoint of a low-risk privacy lover. Without knowing the specific utility functions of Group C members, it is difficult to tell where they predominantly fall, but it is likely that some members of group $\mathrm{C}$ will choose each of the three options. Interestingly, if Meza and Webb's claims about low-risk individuals are accurate, then we will expect a high number of them to remain insured even if they opt-out of behavioral tracking programs (De Meza - Webb 2001). The consequence would be that there would still be a significant pooling effect between high-risk and privacy loving individuals. If on the other hand, Rothschild and Stiglitz claims about low-risk individuals are accurate, then members of Group C will tend to exit insurance altogether and the separating equilibrium will be maintained. 
Table 2. Behavior of consumers in different groups

\begin{tabular}{|l|c|c|c|}
\hline & Insured + Opt-In & Insured + Opt-Out & Uninsured \\
\hline $\begin{array}{c}\text { Group A (Low risk, Privacy } \\
\text { Indifferent) }\end{array}$ & All Group A consumers & - & - \\
\hline $\begin{array}{c}\text { Group B (High Risk, Privacy } \\
\text { Indifferent) }\end{array}$ & - & $\begin{array}{c}\text { Some Group B } \\
\text { consumers }\end{array}$ & $\begin{array}{c}\text { Some Group B } \\
\text { consumers }\end{array}$ \\
\hline Group C (Low Risk, Privacy Lovers) & $\begin{array}{c}\text { Some Group C } \\
\text { consumers }\end{array}$ & $\begin{array}{c}\text { Some Group C } \\
\text { consumers }\end{array}$ & $\begin{array}{c}\text { Some Group C } \\
\text { consumers }\end{array}$ \\
\hline Group D (High Risk Privacy Lovers) & - & $\begin{array}{c}\text { Some Group D } \\
\text { consumers }\end{array}$ & $\begin{array}{c}\text { Some Group D } \\
\text { consumers }\end{array}$ \\
\hline
\end{tabular}

Source: Author.

Members of Group D will have no incentive to choose "Insured + Opt-in", since this would only increase their insurance costs. Thus, given that their insurance costs will increase no matter what, many members of group D will leave the insurance market altogether. Only some riskaverse members of group D will choose "Insured + Opt-Out" and in the long run will have an incentive to change their risky behavior.

In Table 2 I have outlined the general contours of purchasing decisions of members in particular groups. We know that Group A will universally choose "Insured + Opt-In". For the other groups we know they will largely choose between "Insured + Opt-Out" or "Uninsured". Group $\mathrm{C}$ is the only group whose consumers may choose any one of the options. We can be fairly confident of the economic contours of the purchasing decisions as outlined in Table 2. What is less clear is (a) how many individuals belong to each group and (b) what are the distributional breakdowns of the choices within each group. These two questions require empirical research.

Given these decisions to purchase insurance, what is the consequence for the desiderata? Group A opts in to the behavioral tracking system and hence the cost based on their risk will be properly internalized based on the behavioral tracking data. Additionally, because they are being monitored, they will have an incentive to maintain low risk to ensure they continue to qualify for lower premiums. The upshot is they are rewarded for their low levels of risk.

Group B members will choose not to participate in the behavioral tracking program due to their known high levels of risk. Insurance firms know that members from Group B will selfselect out of the behavioral tracking program and hence charge higher rates to those individuals opting out, thus internalizing the cost of riskier behavior. The insurance rates for people who choose "Insured + Opt-Out" will therefore be higher than they were before the introduction of the behavioral tracking program. Due to these higher rates, some members of group B may decline insurance altogether since the marginal price increase may make insurance too costly for them. This is an improvement from the standpoint of economic efficiency, but shortly I discuss why this may actually be a sub-optimal social result. The consequence for Group B is that cost is properly internalized, that they have an incentive to decrease risk (since they qualify for lower premiums at that point) and they are punished for their high risk behavior by having to pay a higher premium until they are able to lower their risk. 
Members of Group C will choose any of the three alternatives depending on the specific details of their utility functions. The upshot however is that in any case, a member of Group C will likely suffer relative to their original situation prior to the adoption of behavioral tracking programs by the insurance company. If a member from Group $\mathrm{C}$ adopts the program, they will gain a premium reduction but suffer a privacy loss. If they choose to remain insured but opt out of the behavioral tracking program then they will be pooled into the high-risk group and pay more for the same coverage, despite actually being a low-risk group. Finally, they may choose to go uninsured altogether because the increased cost will not be worth it given their low risk. However, this is a perverse result because if they do suffer an accident, they will be uninsured. The consequence is that low-risk privacy lovers are punished for their privacy loving preferences. Finally, members of Group $\mathrm{D}$ will either remain insured but opt out of the program or decide to go uninsured altogether. Incidentally, members of Group D are correctly pooled and so their costs are properly internalized.

So what is the consequence of the insurance market adopting technologies for behavioral tracking? Without knowing the size of the respective groups and the actual utility functions of most consumers within each group, it is hard to determine whether this is an actual Paretoimprovement. What is apparent is that when we factor in consumer preferences for privacy, there are considerably greater trade-offs than the model originally implied.

The upshot is that for individuals who are willing to part with their privacy, the costs of their actions better represent their risks. This is a victory for cost-internalization, but it comes at the expense of cost-externalization for those in low-risk groups who are unwilling to accept privacy loss. Whether cost internalization exceeds cost externalization depends both on the size of Group A relative to the size of Group C, as well as the average savings (or loss) for each group. Overall, groups A and B have better incentives than they did previously, while incentives for groups $\mathrm{C}$ and $\mathrm{D}$ have not gotten any worse.

The final desiderata are social risk. As Rothschild and Stiglitz (1978) originally noted, the presence of high and low risk groups makes it possible that there is no stable equilibria, which of course is sub-optimal for the insurance market in general. The introduction of behavioral tracking allows for an equilibria to be established which likely reduces volatility in the insurance markets. This is an improvement from the prior situation, however, there is also likely to be an increased number of uninsured individuals from groups $\mathrm{C}, \mathrm{B}$, and D. Traditional economic analysis would regard an increased rate of uninsured individuals in groups B and D as being efficient. This is because the expected value of their insurance policies exceeds the policy's costs. Only the increased uninsured rate of Group $\mathrm{C}$ would be viewed as market inefficiency. However, the conclusions of the traditional economic analysis rest on two problematic assumptions: (1) that the individuals in question have properly assessed their relative levels of risk and utility, (2) that there are well-functioning credits markets for those with inadequate levels of income to purchase insurance. Behavioral irrationality and wealth effects can distort an agent's purchasing decisions from the optimum. The agent's decision not to purchase insurance may more likely be the result of inadequate knowledge, insufficient savings, and disregard of risks posed to other family members (e.g., the loss of household income). Furthermore, in many developed countries there is increased social concern about the plight of the uninsured, most notably in the case of health insurance (Mckee et al. 2013). Possessing health insurance is increasingly being regarded as a fundamental right or at-least a social imperative. Given both the considerations of economic uncertainty and the social imperatives, the increase of uninsured individuals in groups B and D may be less socially optimal than originally implied. 
Table 3. The balance sheet in a competitive market

\begin{tabular}{|l|c|c|}
\hline Dimension & Positive changes & Negative changes \\
\hline Efficiency & $\begin{array}{c}\text { Cost-internalization for Group A, Group B, } \\
\text { and Group D. }\end{array}$ & $\begin{array}{c}\text { Group C Costs: either (1) privacy loss for } \\
\text { those who choose "Insured + Opt-In," } \\
\text { (2) cost-externalization for those who } \\
\text { choose "Insured + Opt-Out," (3) } \\
\text { increased risk for members who choose } \\
\text { "Uninsured". }\end{array}$ \\
\hline Incentives & $\begin{array}{c}\text { Group A and B and members of C that opt- } \\
\text { in to the Program, have better Incentives. }\end{array}$ & - \\
\hline Reward/punishment & $\begin{array}{c}\text { Group A is rewarded for reducing social } \\
\text { risk Group B and Group D is punished for } \\
\text { increasing social risk. }\end{array}$ & $\begin{array}{c}\text { Group C is punished for privacy loving } \\
\text { preferences. }\end{array}$ \\
\hline Social risk & $\begin{array}{c}\text { Decreased risk volatility in the insurance } \\
\text { market (as a consequence from higher risk } \\
\text { group internalization). }\end{array}$ & An increased number of uninsured \\
individuals from groups B, C, and D
\end{tabular}

Source: Author.

Given all of the considered factors, how does behavioral tracking of social risk compare to the previous system where there was no behavioral tracking but more cost-externalization? Table 3 compares the positive and negative changes that the introduction of BTTs has on a competitive insurance market.

\section{RISKS FROM COST-INTERNALIZATION OF BEHAVIORAL EXTERNALITIES IN A COMPETITIVE MARKET WITH A UNIVERSAL MANDATE}

When individuals are allowed to opt-out of BTT, the result is a partially pooling equilibrium with the negative consequences being significant inefficiencies for members of Group C, as well as an increase in the number of uninsured individuals from groups B, C, and D. One potentially effective solution to both of these problems involves instituting a Universal Opt-In Insurance Mandate. According to such a mandate, every individual has to be insured and is required to participate in the BTT program. Such a solution essentially collapses groups A and C together into a single low-risk group and groups $\mathrm{B}$ and $\mathrm{D}$ together into a high-risk group.

Under a Universal Opt-in Insurance Mandate all individuals are required to participate in the behavioral tracking program, which means that insurers know the behavioral risk posed by each individual. Such a mandate has the advantage of cleaving low and high-risk groups into a perfectly separating equilibrium and results in cost-internalization, robust incentives, and fair rewards/punishments. Such a mandate might make sense in the context of certain forms of insurance, notably, liability insurance and health insurance.

Nevertheless, such a universal mandate comes with considerable trade-offs. First, Group C and Group D still suffer utility losses as a consequence of their privacy loving preferences being 
Table 4. The balance sheet of a competitive market with a universal opt-in insurance mandate

\begin{tabular}{|l|c|c|}
\hline Dimension & Positive changes & Negative changes \\
\hline Efficiency & $\begin{array}{r}\text { Groups A, B, C, and D costs are fully } \\
\text { internalized. }\end{array}$ & $\begin{array}{c}\text { Group C and Group D suffer utility losses } \\
\text { from privacy costs. }\end{array}$ \\
\hline Incentives & $\begin{array}{r}\text { Groups A and C are incentivized to } \\
\text { maintain low risk. }\end{array}$ & - \\
\cline { 2 - 3 } & $\begin{array}{r}\text { Groups B and D are incentivized to } \\
\text { decrease risk. }\end{array}$ & \\
\hline Reward/punishment & Groups A and C are rewarded for low risk. & \\
\cline { 2 - 2 } & Groups B and D are punished for high risk. & \\
\hline Social risk & All groups are fully insured. & $\begin{array}{r}\text { Systemic violation of privacy rights and } \\
\text { possible threat to civil liberties. }\end{array}$ \\
\hline
\end{tabular}

Source: Author.

ignored. Furthermore, while the social risk of the uninsured has been eliminated, another social risk has taken its place; the violation of privacy rights. Requiring individuals to opt-in is a rights violation in this case because their consent is completely undermined, individuals cannot optout of being behaviorally tracked. ${ }^{5}$

Governments differ from private organizations in that they have the authority to alter the legal institutions and are known to do so in order to implement and maintain large scale programs. Given that the government has the unique power to alter the rules of the game, there may be a legitimate concern that governments may facilitate the program for the express purpose of making legal cost-internalization programs that undermine privacy rights. For example, if behavioral cost-internalization takes place in the context of socialized healthcare, governments could give themselves the legal power to review a person's credit card data for the purpose of evaluating their dietary habits to determine the size of that person's health insurance premiums. Such shrinking of legal rules would probably not happen all at once, but may happen through a cumulative process of scope creep.

The increasing role of government involvement in healthcare may result in an increasing role of government involvement in the monitoring of citizens' behavioral health choices. This would be morally problematic for reasons beyond privacy. Behavioral health choices comprise a significant aspect of our personal lives. Religious and moral beliefs such as decisions to be vegetarian, vegan, or kosher may prevent an individual from eating a "balanced diet." Many people get enormous joy and fulfillment from risky recreational activities such as mountain-climbing, boxing, motorcycle riding, base jumping, hang gliding, boating, and cave diving, yet all of these involve considerable personal risk. Would these highly personal dietary and recreational behaviors count against one's health premium in a hypothetical future government program? The upshot of these considerations is that a universal opt-in mandate poses a serious threat to

${ }^{5}$ For an articulation of how lack of consent undermines rights, see Korsgaard (1996). 
privacy rights and perhaps undermines civil liberties by creating a situation in which the state monitors citizens' behavioral activities in an intrusive and patronizing manner. ${ }^{6}$ Table 4 compares the positive and negative changes from a Universal Opt-in Insurance Mandate.

\section{CONCLUSION}

Internalizing behavioral externalities is a tempting approach to alleviating social costs, as it unites the goal of economic efficiency with a sense of responsibilitarian justice. Yet, we have seen that the introduction of behavioral tracking technologies does not result in a straightforward separating equilibrium between low and high risk individuals. The advantage of BTTs is that they make possible the creation of a custom price, unique to the behavioral risks posed by each individual consumer. The problem is that the monitoring required to create a unique price necessarily creates a privacy concern. The consequence is that there is a pooling effect between privacy lovers and high risk individuals. Since we lack a mechanism by which to separate real privacy lovers from high-risk individuals, then there will always be a pooling problem. The introduction of BTTs causes inefficiencies for privacy lovers and also creates a social risk where more people are pushed out of the insurance market altogether. The solution to this pooling problem and the problem of the uninsured is to eliminate the ability of consumers to opt-out of the BTT program. However this solution makes the privacy concern even worse. Hence, the introduction of BTTs creates an inexorable tradeoff between privacy and efficiency.

What this analysis reveals is that the decision by others to opt-in to the behavioral tracking systems is not an isolated choice, but also has an effect on the costs of privacy to other individuals. As more people opt-in to these systems, the cost for preserving privacy increases for everyone else. Privacy is supposedly the quintessential "private good," but it might turn out that each individual's personal decision to relinquish it may pose a greater social cost than the private benefit accrued to that person. Each privacy surrender moves us closer to a society in which the default price of a good is determined by the aggregate risk-factor of those who have given up their privacy interests. That higher default price in turn raises the cost of personal privacy for everyone else. This ratcheting effect may make the cost of valuing privacy so high that privacy itself is priced out of the market.

\section{REFERENCES}

Anderson, E. (1999): What is the Point of Equality? Ethics 109(2): 287-337.

Buchanan, J. - Tullock, G. (1965): The Calculus of Consent: Logical Foundations of Constitutional Democracy. Ann Arbor: University of Michigan Press.

De Meza, D. - Webb, D. (2001): Advantageous Selection in Insurance Markets. RAND Journal of Economics 32(2): 249-262.

\footnotetext{
6 "Such a system requires the state to make grossly intrusive, moralizing judgments of individual's choices" (Anderson 1999).
} 
Dworkin, R. (1981): What is Equality? Part 2: Equality of Resources. Philosophy and Public Affairs 10(4): 283-345.

Guerrini, C. J. - Robinson, J. O. - Petersen, D. - McGuire, A. (2018): Should Police Have Access to Genetic Genealogy Databases? Capturing the Golden State Killer and Other Criminals Using a Controversial New Forensic Technique. PLoS Biology 16(10).

Guillen, M. - Nielsen, J. P. - Ayuso, M. - Perez-Marin, A. M. (2018): The Use of Telematics Devices to Improve Automobile Insurance Rates. Risk Analysis 39(3): 662-672.

Husnjak, S. - Peraković, D. - Forenbacher, I. - Mumdziev, M. (2015): Telematics System in Usage Based Motor Insurance. Procedia Engineering 100: 816-825.

Korsgaard, C. (1996): Creating the Kingdom of Ends. Cambridge: Cambridge University Press.

McKee, M. - Balabanova D. - Basu S. - Ricciardi W. - Stuckler D. (2013): Universal Health Coverage: A Quest for All Countries but Under Threat in Some. Value in Health 16(1): 39-45.

Newman, N. (2014): The Costs of Lost Privacy: Consumer Harm and Rising Economic Inequality in the Age of Google. William-Mitchell Law Review 40(2): 12.

Pigou, A. C. (2013): The Economics of Welfare. New York: St. Martin's Press, Palgrave Macmillan.

Richards, N. M. (2013): The Dangers of Surveillance, Harvard Law Review 126: 1934-1965.

Rothschild, M. - Stiglitz, J. (1978): Equilibrium in Competitive Insurance Markets: An Essay on the Economics of Imperfect Information. In: Diamond, P. - Rothschild, M. (Eds.): Uncertainty in Economics. Cambridge: Academic Press.

Spence, M. (1978): Product Differentiation and Performance in Insurance Markets. Journal of Public Economics 10(3): 427-447.

Wilson, C. (1976): A Model of Insurance with Asymmetric Information. Cowles Foundation for Research in Economics Discussion Paper No. 432/1976.

Zuboff, S. (2015): Big Other: Surveillance Capitalism and the Prospects of an Information Civilization. Journal of Information Technology 30(1): 75-89.

Open Access. This is an open-access article distributed under the terms of the Creative Commons Attribution-NonCommercial 4.0 International License (https://creativecommons.org/licenses/by-nc/4.0/), which permits unrestricted use, distribution, and reproduction in any medium for non-commercial purposes, provided the original author and source are credited, a link to the CC License is provided, and changes - if any - are indicated. 